\title{
Poisson's Ratios of Technological Materials
}

\author{
Arthur Ballato \\ US Army Communications-Electronics RDEC \\ Fort Monmouth, NJ 07703-5201, USA \\ a.ballato@IEEE.org
}

\begin{abstract}
Poisson's ratio (PR), the relation between lateral contraction of an elastic rod when subjected to a longitudinal extension, has a long and interesting history. For isotropic bodies, it can theoretically range from $+1 / 2$ to -1 ; the experimental gamut for anisotropic materials is even larger. For the vast majority of materials the $P R$ is positive for all combinations of directions. But as far back as the 1800 s, Voigt and others found that for some materials negative values were encountered. Negative PR (nPR) values remained for many years merely a curiosity, but more recently some of the interesting technological consequences have come to be recognized [1-3]. Some of the counterintuitive acoustic possibilities of nPRs are analogous, in a certain fashion, to those arising with negative refraction electromagnetic materials [4]. Even when a material does not have nPR properties, if it is piezoelectric, then the $P R$ can be altered, sometimes by appreciable amounts, by changing the electrical boundary conditions [5-6]. We review Poisson's ratio in crystals, describing technologically important materials that have small, or negative PRs. Potential applications of the nPR property are also mentioned.
\end{abstract}

\section{INTRODUCTION}

Poisson's Ratio ( $v$ ) is defined as the ratio of lateral contraction to longitudinal extension strains when a bar is subjected to a terminal tractive load, in the limit as the crosssection vanishes [7]. Originally formulated for isotropic solids, the definition carries over logically to anisotropic bodies [8-9]. Isotropic bodies are constrained thermodynamically to the range $+1 / 2>v>-1$. Current interest centers around materials having PRs that exceed these limits by virtue of natural or artificial anisotropy [1029]. Whereas laws of physics govern conservation of various fluxes (mass, energy, linear \& angular momentum), there is no such law requiring the conservation of volume, and the variety of extant PR values stem from this fact. Of particular interest are nPR substances; these have been termed "auxetic" by Evans, et al. [18]. Some of the generic structures, attributes, and uses of such materials, particularly the auxetics, are the following.

Structures: Reentrant cellular foams, solids, and honeycombs, microporous polymers, laminates and composites (specifically piezo-polymer), hinged structures, convoluted ribbed and chiral (helical) chains, Cosserat/ Mindlin microstructural materials (45 constants), and ordinary crystals (Systems I to IX).

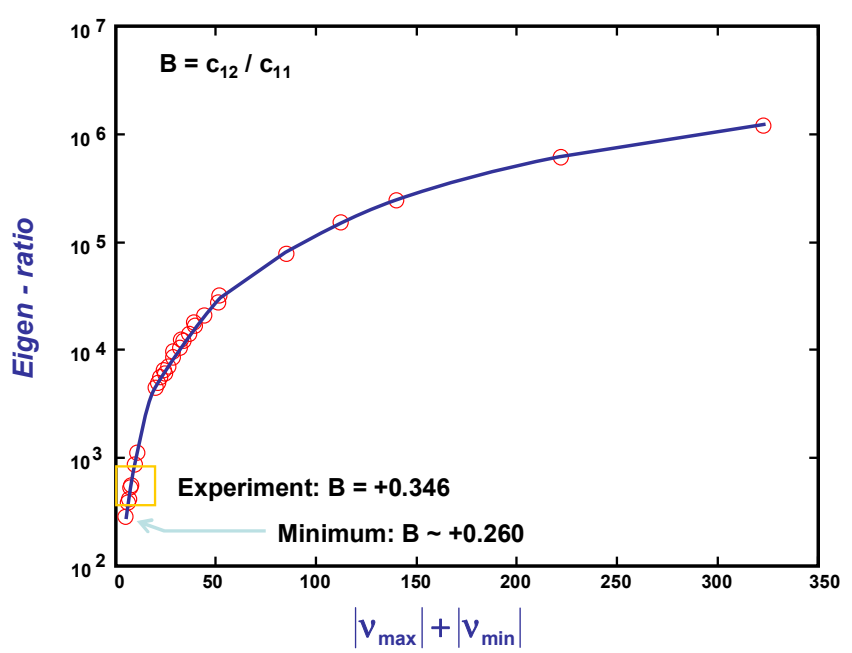

Figure 1. Eigen-ratio vs. PR for lanthanum niobate.

Conjectured attributes: Increased resilience, enhanced shear moduli, indentation resistance, fracture toughness, increased tear resistance, thermal shock resistance.

Conjectured uses: Micro- and nano-electronics; materials for substrate films; substrate/epitaxial layers subjected to temperature gradients, fluctuations; mitigation of forcefrequency effect [30], which depends conjointly upon $c_{\lambda \mu \tau}$ and PR; study of structural phase transitions (austeniticmartensitic); increased stress decay rate with distance; ameliorated stress distributions around apertures and cracks (fracture mechanics); sandwich panels for aircraft and automobiles; piezocoupling enhancement in composites [3]; fasteners; miniaturized piezoelectric hydrophone sensors; enhanced dispersion, enabling acoustic sponges, shockabsorbers, air filters, etc.; novel acoustic transmission/ reflection properties [31]. 


\section{CRystals [32-33]}

We limit the discussion to crystals, described by a linear stiffness [c] or compliance [s] matrix. For crystals of arbitrary anisotropy, Bechmann tabulated the relations for rotations of these matrices, from which the PRs may be calculated [34]. PR requires specification of two orthogonal directions: the direction of tensile stress (that we take as the rotated $X_{1}$ axis), and the lateral direction of strain (taken as the rotated $\mathrm{X}_{2}$ axis). The IEEE axial convention for three coordinate rotations is $(\mathrm{YXw} \ell \mathrm{t}) \varphi / \theta / \psi$, specifying a first rotation about the $X_{3}$ axis by angle $\varphi$, a second rotation about the resulting $\mathrm{X}_{1}{ }^{\prime}$ axis by angle $\theta$, and a third rotation about the resulting $\mathrm{X}_{2}$ " axis by angle $\psi$ [32-33]. In the resulting $\mathrm{X}^{\prime \prime}$, coordinate system, the rotated $X_{1}$ axis is determined solely by the angles $\varphi$ and $\psi$. Likewise, the rotated $X_{2}$ axis is determined solely by the angles $\varphi$ and $\theta$.

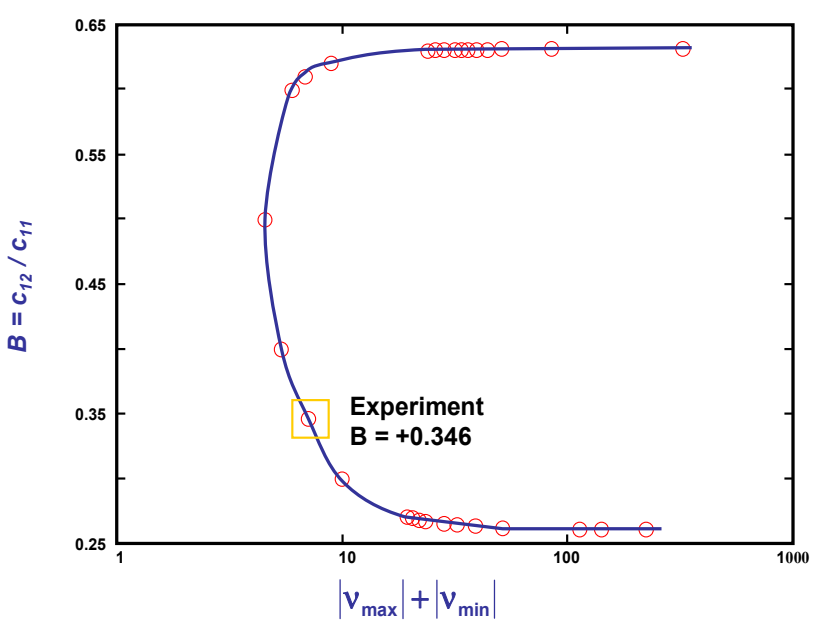

Figure 2. Change in PR by altering $\mathrm{c}_{12} / \mathrm{c}_{11}$.

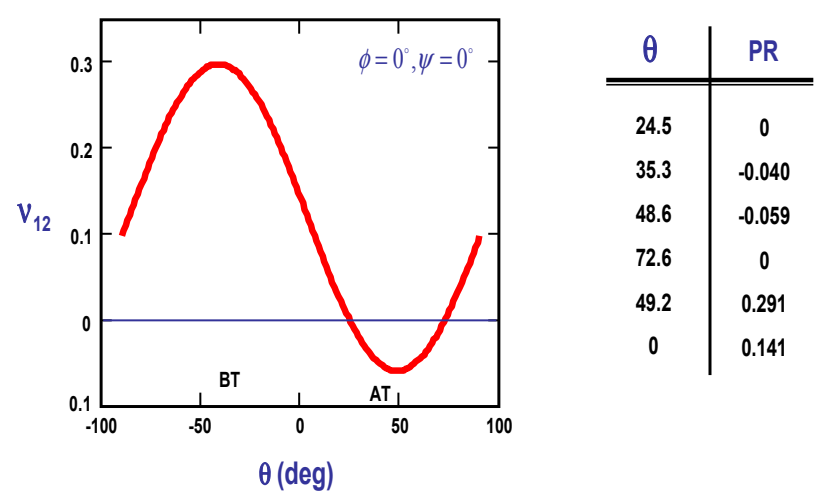

Figure 3. PR of alpha-quartz rotated-y-cuts.
Because the stored energy density of a crystal must be positive, the elastic matrix is constrained to be positive definite (PD) [35-36]. A matrix is PD iff: a) the principal minors are strictly positive, or $b$ ) the leading principal minors are strictly positive, or c) all eigenvalues (EVs) are positive. This last criterion was stated in equivalent terms for the elastic problem by Lord Kelvin [37]. We use this in the sequel; in particular, the ratio of the maximum to minimum EV is used to investigate the limits of stability and is correlated with magnitude of the PR. Whereas the EVs of [c] and [s] are different, this eigenvalue ratio (ER) is the same for both.

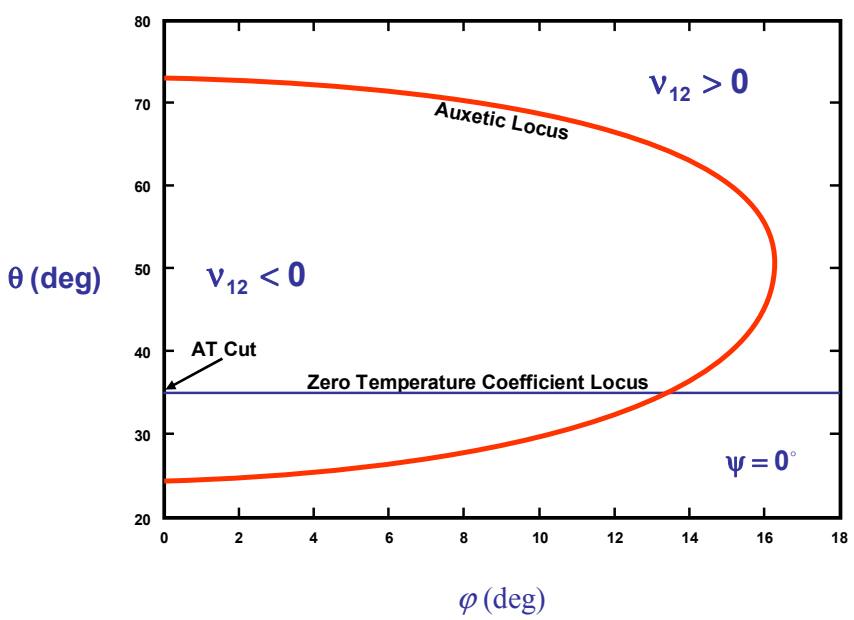

Figure 4. Auxetic locus of alpha-quartz for $\psi=0^{\circ}$.

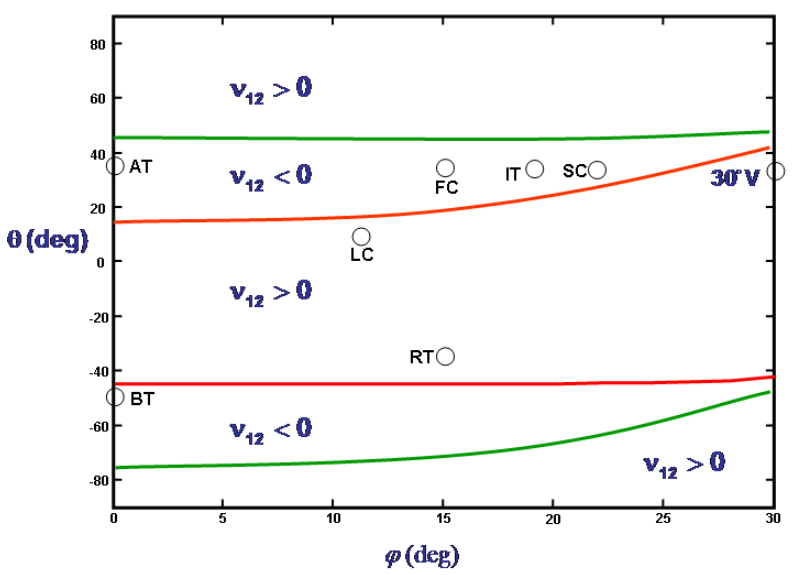

Figure 5. Auxetic Loci of alpha-quartz for $\psi=90^{\circ}$ 


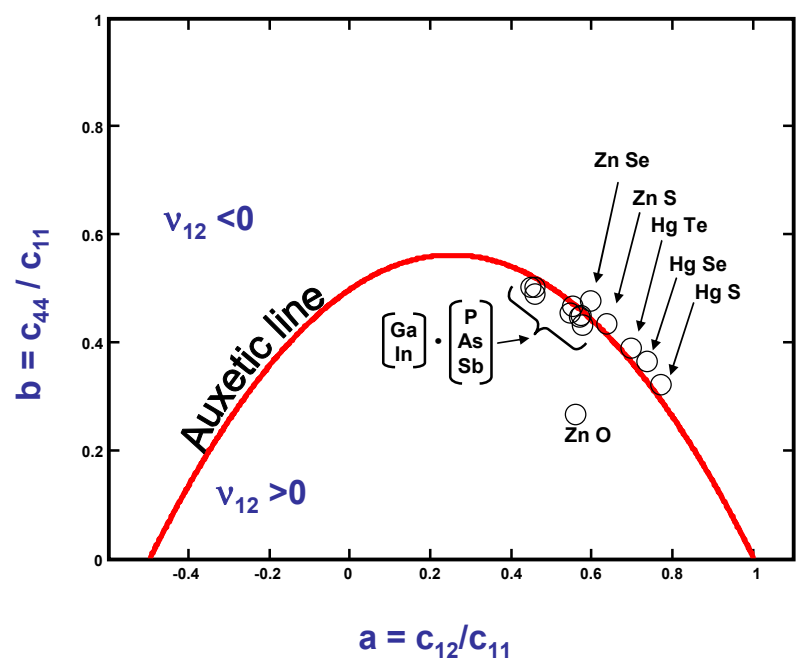

Figure 6. Binary semiconductors plotted with auxetic locus.

Tables 1, 2 and 3 list various PRs for a variety of crystals in the monoclinic, rhombic, and cubic systems. Data for these tables are taken from [38-39], which contain citations to the original literature. In each case the complete angle space was searched to find the maximum and minimum values of $v$; also given are values for the aggregate $\langle\boldsymbol{v}\rangle$, determined by the iterative procedure given in [40-41]. The listing of cubics has been chosen to contain only auxetics; $v_{[111]}$ is independent of rotation about the three-fold axis. The PR $v_{[100]}$ notation denotes that the two PR cubic axes are aligned along equivalent [100] directions.

The entries in Tables 1 and 2 are arranged in order of increasing ER; the symbol $\Sigma$ denotes the sum of the absolute values of the PRs. One sees a rough correlation between these two measures. The last entry, $\mathrm{LaNbO}_{4}$, has a rather large value of PR. In Figure 1, its ER is plotted against $\Sigma$ when the ratio $B=c_{12} / c_{11}$ is varied. The experimental value is shown to be close to the minimum ER. Figure 2 similarly plots $B$ against $\Sigma$. It is seen that the PR increases to arbitrarily large values as the values of $B$ reach the limits for lattice stability.

Table I. Poisson's ratios for some monoclinic crystals.

\begin{tabular}{|c|c|c|c|c|c|c|c|}
\hline Material & Formula & Class & $v_{\text {Von }}$ & $\mathbf{v}_{\min }$ & $\langle v\rangle$ & $\Sigma$ & eigen-ratio \\
\hline diopside & $\mathrm{CaMgSi}_{2} \mathrm{O}_{6}$ & $2 / \mathrm{m}$ & +0.483 & +0.100 & +0.252 & 0.583 & 6.46 \\
\hline lithium sulfate monohydrate & $\mathrm{Li}_{2} \mathrm{SO}_{4} \cdot \mathrm{H}_{2} \mathrm{O}$ & 2 & +0.470 & -0.027 & +0.250 & 0.497 & 6.53 \\
\hline bismuth vanadate & $\mathrm{BiVO}_{4}$ & $2 / \mathrm{m}$ & +0.682 & -0.033 & +0.248 & 0.715 & 6.6 \\
\hline cosite & $\mathrm{SiO}_{2}$ & $2 / \mathrm{m}$ & +0.734 & -0.109 & +0.271 & 0.843 & 6.9 \\
\hline potassium tartrate hemihydrate & $\mathrm{K}_{2} \mathrm{C}_{4} \mathrm{H}_{4} \mathrm{O}_{8} \cdot \mathrm{H}_{2} \mathrm{O}$ & 2 & +0.529 & +0.139 & +0.318 & 0.668 & 9.88 \\
\hline orthoclase & $\mathrm{KAlSi}_{3} \mathrm{O}_{8}$ & $2 / \mathrm{m}$ & +0.768 & -0.169 & +0.296 & 0.937 & 11.5 \\
\hline triglycine sulfate (TGS) & $\left(\mathrm{NH}_{2} \mathrm{CH}_{2} \mathrm{COOH}\right)_{3} \cdot \mathrm{H}_{2} \mathrm{SO}_{4}$ & 2 & +0.864 & -0.040 & +0.357 & 0.904 & 13.6 \\
\hline ethylenediamine tartrate (EDT) & $\mathrm{C}_{6} \mathrm{H}_{14} \mathrm{~N}_{2} \mathrm{O}_{6}$ & 2 & +1.257 & -0.005 & +0.332 & 1.262 & 16.7 \\
\hline calcium sulfate dihydrate (gypsum) & $\mathrm{CaSO}_{4} \cdot 2 \mathrm{H}_{2} \mathrm{O}$ & $2 / \mathrm{m}$ & +0.704 & -0.120 & +0.341 & 0.824 & 17.2 \\
\hline zirconium oxide & $\mathrm{ZrO}_{2}$ & $2 / \mathrm{m}$ & +0.581 & -0.631 & +0.267 & 1.212 & 21.7 \\
\hline$d$-tartaric acid & $\mathrm{H}_{2} \mathrm{C}_{4} \mathrm{H}_{4} \mathrm{O}_{6}=\mathrm{C}_{4} \mathrm{H}_{6} \mathrm{O}_{8}$ & 2 & +0.888 & -0.211 & +0.325 & 1.099 & 23.3 \\
\hline cesium deuterium selenite & $\mathrm{CsD}\left(\mathrm{SeO}_{3}\right)$ & $2 / \mathrm{m}$ & +1.030 & -0.303 & +0.377 & 1.333 & 28.5 \\
\hline sodium thiosulfate pentahydrate & $\mathrm{Na}_{2} \mathrm{~S}_{2} \mathrm{O}_{3} 5 \mathrm{H}_{2} \mathrm{O}$ & $2 / \mathrm{m}$ & +1.264 & -1.125 & +0.363 & 2.389 & 34.8 \\
\hline cesium dihydrogen phosphate & $\mathrm{CsH}_{2} \mathrm{PO}_{4}$ & $2 / \mathrm{m}$ & +2.701 & -1.926 & +0.397 & 4.627 & 237. \\
\hline lanthium niobate & $\mathrm{LaNbO}_{4}$ & $2 / \mathrm{m}$ & +3.953 & -3.011 & +0.451 & 6.964 & 571. \\
\hline
\end{tabular}

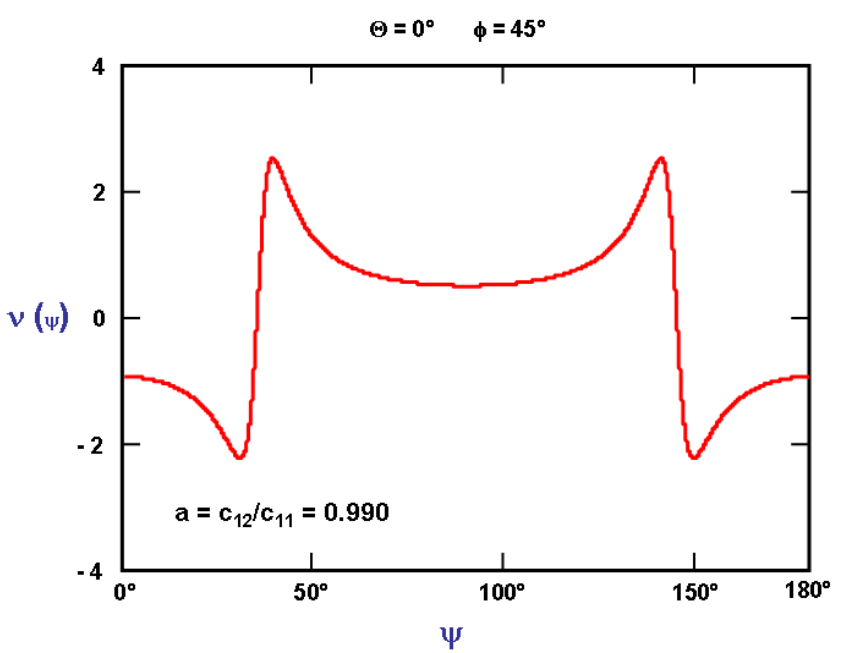

Figure 7. Poisson's Ratio for cubics with $\psi=45^{\circ}, \theta=0^{\circ}$ and $\mathrm{c}_{12} / \mathrm{c}_{11}$ near the point of instability.

Table II. Poisson's ratios for some rhombic crystals.

\begin{tabular}{|c|c|c|c|c|c|c|c|}
\hline Material & Formula & Class & $v_{\max }$ & $v_{\min }$ & $\langle\phi$ & $\Sigma$ & eigen-ratio \\
\hline topaz & $\mathrm{Al}_{2} \mathrm{SiO}_{4}(\mathrm{~F}, \mathrm{OH})_{2}$ & $\mathrm{mmm}$ & +0.391 & +0.069 & +0.221 & 0.460 & 4.75 \\
\hline uranium & $\alpha=U$ & $\mathrm{mmm}$ & +0.545 & -0.017 & +0.201 & 0.562 & 4.89 \\
\hline chrysoberyl & $\mathrm{BeAl}_{2} \mathrm{O}_{4}$ & $\mathrm{mmm}$ & +0.293 & +0.150 & +0.229 & 0.443 & 5.00 \\
\hline barium sodium niobate (BSN) & $\mathrm{Ba}_{2} \mathrm{NaNb}_{5} \mathrm{O}_{15}$ & $\mathrm{~mm} 2$ & +0.385 & +0.141 & +0.239 & 0.526 & 5.69 \\
\hline forsterite & $\mathrm{Mg}_{2} \mathrm{SiO}_{4}$ & $\mathrm{mmm}$ & +0.330 & +0.138 & +0.239 & 0.468 & 6.10 \\
\hline tellurium vanadate & $\mathrm{Te}_{2} \mathrm{~V}_{2} \mathrm{O}_{9}$ & $\mathrm{~mm} 2$ & +0.442 & +0.045 & +0.199 & 0.487 & 6.64 \\
\hline aragonite & $\mathrm{CaCO}_{3}$ & $\mathrm{mmm}$ & +0.737 & -0.062 & +0.177 & 0.499 & 6.87 \\
\hline zinc antimonide & $\mathrm{ZnSb}$ & $\mathrm{mmm}$ & +0.460 & +0.039 & +0.255 & 0.499 & 7.64 \\
\hline lithium germanate & $\mathrm{Li}_{2} \mathrm{Ge}_{7} \mathrm{O}_{15}$ & $\mathrm{~mm} 2$ & +0.483 & +0.150 & +0.274 & 0.633 & 7.74 \\
\hline cadmium antimonide & CdSb & $\mathrm{mmm}$ & +0.612 & +0.059 & +0.237 & 0.671 & 9.35 \\
\hline polyvinylidene fluoride (PVDF) & $-\left(\mathrm{CH}_{2} \mathrm{CF}_{2}\right)_{n}$ - & $\mathrm{mm} 2$ & +0.690 & -0.632 & +0.343 & 1.322 & 10.7. \\
\hline lithium ammonium tartrate & $\mathrm{LiNH}_{4} \mathrm{C}_{4} \mathrm{O}_{6} \cdot \mathrm{H}_{2} \mathrm{O}$ & 222 & +0.540 & +0.107 & +0.315 & 0.647 & 12.3 \\
\hline lithium formate & $\mathrm{LiCOOH} \bullet \mathrm{H}_{2} \mathrm{O}$ & $\mathrm{mm} 2$ & +0.640 & +0.096 & +0.304 & 0.736 & 13.1 \\
\hline barite & $\mathrm{BaSO}_{4}$ & $\mathrm{mmm}$ & +0.616 & +0.055 & +0.318 & 0.671 & 13.8 \\
\hline$\beta$-resorcinol & $\mathrm{C}_{6} \mathrm{H}_{4}(\mathrm{OH})_{2}$ & $\mathrm{~mm} 2$ & +0.830 & -0.084 & +0.358 & 0.914 & 14.6 \\
\hline iodine & 1 & $\mathrm{mmm}$ & +1.311 & -0.476 & +0.277 & 1.787 & 15.3 \\
\hline sulfur & $\alpha-S$ & $\mathrm{mmm}$ & +0.614 & +0.101 & +0.345 & 0.715 & 15.6 \\
\hline anhydrite & $\mathrm{CaSO}_{4}$ & $\mathrm{mmm}$ & +0.761 & -0.047 & +0.277 & 0.808 & 21.7 \\
\hline Rochelle salt & $\mathrm{KNa} \mathrm{C}_{4} \mathrm{H}_{4} \mathrm{O}_{6} \bullet 4 \mathrm{H}_{2} \mathrm{O}$ & 222 & +0.866 & -0.044 & +0.386 & 0.910 & 35.1 \\
\hline sodium ammonium tartrate & $\mathrm{Na}\left(\mathrm{NH}_{4}\right) \mathrm{C}_{4} \mathrm{H}_{4} \mathrm{O}_{6} \bullet 4 \mathrm{H}_{2} \mathrm{O}$ & 222 & +0.920 & -0.084 & +0.406 & 1.004 & 36.5 \\
\hline
\end{tabular}

\section{QUARTZ}

The one trigonal entry that we have space to discuss is that old standby, $\alpha$-quartz. In [42] are some admirable early and accurate PR calculations for quartz. Figure 3 shows the PR as function of the AT-BT angle $\theta$, indicating the presence of auxetic behavior. The $X_{1}$ (digonal) axis is the direction of applied force, and the $X_{2}{ }^{\prime}$ axis is the direction of the thickness of a resonator plate. In the auxetic region (including the AT cut), a compressional force will make the plate thickness diminish, and the frequency will increase. This lattice distortion is, in addition to the third-order elastic constants $\left(c_{\lambda \mu \tau}\right)$, responsible for the force-frequency effect in resonators [30]. Figures 4 and 5 show the quartz auxetic loci when the angle of force application $(\psi)$ is rotated in the plane of the plate. In Fig. 5 it is seen that the zero temperature locus (AT-FC-IT-SC cuts) is located within the auxetic region. The LC and RT cuts are nearly auxetic as well. 


\section{CUBICS}

For cubics, auxetic behavior may be examined by plotting $\mathrm{b}=\mathrm{c}_{44} / \mathrm{c}_{11}$ versus $\mathrm{a}=\mathrm{c}_{12} / \mathrm{c}_{11}$. Limits on $\mathrm{a}$ and $\mathrm{b}$, dictated by energy considerations, are: $-1 / 2<\mathrm{a}<+1$ and $\mathrm{b}>0$. While the extrema of $v_{12}$ are not necessarily those of $v_{12}$ $\{[110][1 \overline{1} 0]\}$, this is ordinarily the case; in any event, the extrema lie on the periphery of the cubic primitive region circumscribed by the great circle paths from [100] to [110] to [111] to [100]; see [27]. For this set of directions, the equation for $v_{12}$ is $[(1-a)(1+2 a)-2 b] /[(1-a)(1+2 a)+$ $2 \mathrm{~b}]$. The auxetic line $\left(v_{12}=0\right)$ has a maximum at $\mathrm{a}=(1 / 2)^{2}, \mathrm{~b}=$ $(3 / 4)^{2}$, and is plotted in Fig. 6 along with data points for an assortment of cubic semiconductors. Many III-V and II-VI binaries [43-44] lie close to the auxetic line. The unary semiconductors $\mathrm{Si}, \mathrm{Ge}$, and $\mathrm{C}(\mathrm{d})$ are not auxetic [45-46]. Global extrema are: $\mathrm{Si}\left(\mathrm{v}_{\max }=+0.360, \mathrm{v}_{\min }=+0.065\right)$; $\mathrm{Ge}$ $\left(\mathrm{v}_{\max }=+0.363, \mathrm{v}_{\min }=+0.025\right) ; \mathrm{C}(\mathrm{d})\left(\mathrm{v}_{\max }=+0.115, \mathrm{v}_{\min }=\right.$ $+0.009)$. For hexagonal $(6 / \mathrm{m} \mathrm{mm})$, dislocation-free graphite, the corresponding figures are $v_{\max }=+0.860, v_{\min }=+0.004$; going from $\mathrm{sp}^{3}$ to $\mathrm{sp}^{2}$ makes quite a difference!

In Fig. $7 v$ is plotted for cubics vs angle $\psi$ for $\varphi=45^{\circ}$ and $\theta=0^{\circ}$. The value of $a=c_{12} / c_{11}$ is 0.990 , a value bordering on the +1 limit for stability. One sees how the PR ratios increase beyond those for actual cubics given above; the extrema occur closer together as well. Whereas the PR bounds for isotropic substances is $-1<v<+1 / 2$ for anisotropic elastic materials the bounds are [24] $-\infty<v<+\infty$; a somewhat larger gamut!

Table III. Poisson's ratios for some auxetic cubic crystals

\begin{tabular}{|c|c|c|c|c|c|}
\hline Substance & $\mathbf{V}_{\max }$ & $V_{\text {min }}$ & $v_{\text {[111] }}$ & $\mathbf{V}_{\text {r1001 }}$ & sy? \\
\hline$\beta-A g l$ & 1.233 & -0.415 & +0.299 & +0.466 & +0.402 \\
\hline $\mathrm{BN}$ & 0.236 & -0.020 & +0.071 & +0.188 & +0.121 \\
\hline $\mathrm{BaTiO}_{3}$ & 0.758 & -0.162 & +0.208 & +0.395 & +0.304 \\
\hline $\mathrm{CdTe}$ & 0.698 & -0.011 & +0.295 & +0.408 & +0.351 \\
\hline $\mathrm{CuCl}$ & 0.855 & -0.070 & +0.345 & +0.444 & +0.397 \\
\hline $\mathrm{CuBr}$ & 0.911 & -0.135 & +0.328 & +0.445 & +0.391 \\
\hline Cul & 0.704 & -0.034 & +0.281 & +0.405 & +0.343 \\
\hline$\beta-\mathrm{HgS}$ & 0.799 & -0.044 & +0.329 & +0.433 & +0.383 \\
\hline $\mathrm{HgSe}$ & 0.774 & -0.055 & +0.306 & +0.423 & +0.366 \\
\hline $\mathrm{HgTe}$ & 0.713 & -0.031 & +0.289 & +0.409 & +0.348 \\
\hline LiF & 0.422 & -0.027 & +0.144 & +0.291 & +0.211 \\
\hline $\mathrm{MgAl}_{2} \mathrm{O}_{4}$ & 0.584 & -0.070 & +0.190 & +0.353 & +0.268 \\
\hline $\mathrm{Ni}$ & 0.677 & -0.085 & +0.227 & +0.384 & +0.305 \\
\hline $\mathrm{Ni}_{3} \mathrm{Al}$ & 0.780 & -0.178 & 0.208 & 0.398 & 0.307 \\
\hline$\beta-\mathrm{SiC}$ & 0.397 & -0.028 & +0.133 & +0.279 & +0.198 \\
\hline$\beta$-cristobalite-1 & 0.176 & -0.277 & -0.148 & +0.121 & -0.031 \\
\hline$\beta$-cristobalite-2 & 0.149 & -0.296 & -0.173 & +0.103 & -0.054 \\
\hline$\beta-Z n S$ & 0.649 & -0.025 & +0.257 & +0.388 & +0.321 \\
\hline $\mathrm{ZnSe}$ & 0.611 & -0.035 & +0.230 & +0.371 & +0.298 \\
\hline
\end{tabular}

\section{PIEZOELECTRIC CRYSTALS}

In piezoelectrics, the electrical boundary conditions (BCs) must be taken into account [5-6]. The effect on PR of opencircuit (OC) and short-circuit (SC) BCs is shown in Table 4 for crystals with a variety of point group symmetries. The conditions OC and SC correspond, respectively, to imposition of constant $\mathrm{D}$ and $\mathrm{E}$ constraints.

\section{CONCLUSIONS}

Bounds on Poisson's Ratio:

- Isotropics: $-1<\mathrm{v}<+1 / 2$ (known for many years)

- Crystals: $-\infty<v<+\infty$ (!) (known since 2005)

Artificially varying $c_{\mu \lambda}$ toward lattice instability produces large $|v|$ values:

- $v_{\max }$ and $v_{\text {min }}$ increase in magnitude

- $v_{\max }$ and $v_{\text {min }}$ draw closer in angle

Lattice stability is correlated with eigenvalue ratio:

- A crystal, like diamond, with EVs close to a sixdimensional sphere, is quite stable

Table IV. Effect of electrical boundary conditions on the PRs of various crystals.

\begin{tabular}{|c|c|c|c|c|c|c|c|c|}
\hline Material & Class & $T$ & $v_{\max }(1)$ & $v_{\max }(D)$ & $v_{\min }($ 目) & $v_{\min }(\mathbb{D})$ & $\langle y($ (E) $>$ & $\langle v(D)\rangle$ \\
\hline & & & SC & $O C$ & SC & $O C$ & SC & $O C$ \\
\hline a-quartz & 32 & RT & +0.321 & +0.316 & -0.097 & -0.102 & +0.078 & +0.076 \\
\hline$\beta$-quartz & 622 & $600^{\circ} \mathrm{C}$ & +0.307 & +0.307 & +0.058 & +0.058 & +0.205 & +0.205 \\
\hline$\alpha \cdot \mathrm{TeO}_{2}$ & 422 & $30^{\circ} \mathrm{C}$ & +1.455 & +1.466 & -0.767 & -0.781 & +0.333 & +0.333 \\
\hline$\alpha \cdot \mathrm{TeO}_{2}$ & 422 & Ook & +1.531 & +1.542 & -0.830 & -0.844 & +0.342 & +0.341 \\
\hline $\mathrm{LiNbO}_{3}$ & $3 m$ & RT & +0.388 & +0.327 & +0.137 & +0.076 & +0.251 & +0.198 \\
\hline $\mathrm{LiTaO}_{3}$ & $3 m$ & RT & +0.325 & +0.365 & +0.087 & +0.032 & +0.213 & +0.189 \\
\hline ZnO bulk & $6 \mathrm{~mm}$ & RT & +0.417 & +0.478 & +0.295 & +0.217 & +0.353 & +0.343 \\
\hline ZnO film & $6 \mathrm{~mm}$ & RT & +0.451 & +0.503 & +0.219 & +0.160 & +0.346 & +0.335 \\
\hline LGS & 32 & RT & +0.581 & +0.569 & +0.093 & +0.099 & +0.337 & +0.336 \\
\hline LGN & 32 & RT & +0.625 & +0.611 & +0.073 & +0.079 & +0.350 & +0.348 \\
\hline LGT & 32 & RT & +0.590 & +0.577 & +0.101 & +0.108 & +0.348 & +0.346 \\
\hline $\mathrm{Ob}_{2} \mathrm{KNb}_{5} \mathrm{O}_{15}$ & $\mathrm{~mm} 2$ & RT & +0.476 & +0.284 & +0.124 & +0.153 & +0.258 & +0.215 \\
\hline $\mathrm{LiGaO}_{2}$ & $\mathrm{~mm} 2$ & RT & +0.258 & +0.246 & -0.030 & +0.007 & +0.148 & +0.137 \\
\hline $\mathrm{Li}_{2} \mathrm{GeO}_{3}$ & $\mathrm{~mm} 2$ & RT & +0.338 & +0.329 & +0.090 & +0.097 & +0.243 & +0.236 \\
\hline
\end{tabular}




\section{REFERENCES}

[1] R. Lakes, "Foam structures with a negative Poisson's Ratio," Science, vol. 235, pp. 1038-1040, 27 February 1987.

[2] A. W. Lipsett and A. I. Beltzer, "Reexamination of dynamic problems of elasticity for negative Poisson's ratio," J. Acoust. Soc. Am., vol. 84, no. 6, pp. 2179-2186, December 1988.

[3] W. A. Smith, "Optimizing electromechanical coupling in piezocomposites using polymers with negative Poisson's ratio," IEEE Ultrasonics Symp. Proc., pp. 661-666, Lake Buena Vista, FL, December 1991.

[4] V. G. Veselago, "Properties of materials having simultaneously negative values of the dielectric $\varepsilon$ and the magnetic $\mu$ susceptibilities," Sov. Phys. Solid State, 8, 2854-2856, 1967.

[5] A. Ballato, "Poisson's ratio for piezoceramics," Proc. $10^{\text {th }}$ European Frequency and Time Forum, pp. 127-131, Brighton, UK, March 1996. IEE Conference Publication 418.

[6] A. Ballato, "Alteration of Poisson's ratio in high coupling piezoelectrics," IEEE Intl. Ultrasonics Symp. Proc., pp. 1011-1014, Munich, Germany, October 2002.

[7] S. D. Poisson, "L'équilibre et le mouvement des corps élastiques," Mémoires de l'académie royale des sciences de l'institute de France, vol. 8, pp. 357-570, 1829.

[8] W. G. Cady, Piezoelectricity, McGraw-Hill, New York, 1946; Dover, New York, 1964.

[9] A. Ballato, "Poisson's ratio for tetragonal, hexagonal, and cubic crystals," IEEE Trans. Ultrason., Ferro., Freq. Contr., vol. 43, no. 1, pp. 56-62, January 1996.

[10] B. M. Lempriere, "Poisson's ratio in orthotropic materials," Am. Inst. Aeronaut. Astronaut. J., vol. 6, no. 11, pp. 2226-2227, November 1968.

[11] J. Turley and G. Sines, "The anisotropy of Young's modulus, shear modulus and Poisson's ratio in cubic materials," J. Phys. D: Appl. Phys., vol. 4, pp. 264-271, 1971.

[12] D. J. Gunton and G. A. Saunders, "Stability limits on the Poisson ratio: application to a martensitic transformation," Proc. Roy. Soc. (London), vol. A 343, pp. 63-83, 1975.

[13] Y. Li, "The anisotropic behavior of Poisson's ratio, Young's modulus, and shear modulus in hexagonal crystals," Phys. Stat. Sol. (a), vol. 38, pp. 171-175, 1976.

[14] F. Milstein and K. Huang, "Existence of a negative Poisson ratio in fcc crystals," Phys. Rev. B, vol. 19, no. 4, pp. 2030-2033, 15 February 1979.

[15] J. Rychlewski, “On Hooke's law,” Appl. Math. and Mech. (USSR), vol. 48, no. 3, pp. 303-314, 1984.

[16] K. E. Evans, "Tensile network microstructures exhibiting negative Poisson's ratios," J. Phys. D: Appl. Phys., vol. 22, pp. 1870-1876, 1989.

[17] B. D. Caddock and K. E. Evans, "Microporous materials with negative Poisson's ratios: I. Microstructure and mechanical properties," J. Phys. D: Appl. Phys., vol. 22, pp. 1877-1882, 1989.

[18] K. E. Evans, M. A. Nkansah, I. J. Hutchinson, and S. C. Rogers, "Molecular network design," Nature, vol. 353, no. 6340, p. 124,12 September 1991.

[19] R. Lakes, "Advances in negative Poisson's ratio materials," Adv. Mater., vol. 5, no. 4, pp. 293-296, 1993.

[20] R. H. Baughman, J. M. Shacklette, A. A. Zakhidov, and S. Stafström, "Negative Poisson's ratios as a common feature of cubic metals," Nature, vol. 392, pp. 362-365, 26 March 1998.

[21] Ph. Boulanger and M. Hayes, "Poisson's ratio for orthorhombic materials," J. Elasticity, vol.50, pp. 87-89, 1998.

[22] M. Rovati, "Directions of auxeticity for monoclinic crystals," Scripta Materialia, vol. 51, pp. 1087-1091, 2004.

[23] W. Yang, Z.-M. Li, W. Shi, B.-H. Xie, and M.-B. Yang, "Review on auxetic materials," J. Materials Science, vol. 39, pp. 3269-3279, 2004.
[24] T. C. T. Ting and T. Chen, "Poisson's ratio for anisotropic elastic materials can have no bounds," Q. Jl. Mech. Appl. Math., vol. 58, no. 1, pp. 73-82, 2005.

[25] T. C. T. Ting and D. M. Barnett, "Negative Poisson's ratios in anisotropic linear elastic media,” J. Appl. Mech., vol. 72, pp. 929-931, November 2005.

[26] A. N. Norris, "Extreme values of Poisson's ratio and other engineering moduli in anisotropic materials," J. Mech. Mater. Struct., vol. 1, no. 4, pp. 793-812, 2006.

[27] A. N. Norris, "Poisson's ratio in cubic materials," Proc. Roy. Soc., vol. A462, pp. 3385-3405, 2006.

[28] A. N. Norris, "Extreme values of Poisson's ratio and other engineering moduli in anisotropic materials," J. Mech. Materials Struct., vol. 1, no. 4, pp. 793-812, 2006.

[29] L. D. Peel, "Exploration of high and negative Poisson's ratio elastomermatrix laminates," phys. stat. sol. (b), vol. 244, no. 3, pp. 988-1003, 2007.

[30] P. C. Y. Lee, Y. S. Wang, and X. Markenscoff, "High-frequency vibrations of crystal plates under initial stresses," J. Acoust. Soc. Am., vol. 57, no. 1, pp. 95-105, January 1975 .

[31] A. W. Lipsett and A. I. Beltzer, "Reexamination of dynamic problems of elasticity for negative Poisson's ratio," J. Acoust. Soc. Am., vol. 84, no. 6, pp. 2179-2186, December 1988.

[32] IRE Standards on Piezoelectric Crystals, Proc. IRE, vol. 37, no. 12, pp. 1378-1395, 1949.

[33] IEEE Standard on Piezoelectricity, ANSI/IEEE Std 176-1987, 74 pp., IEEE, New York.

[34] R. Bechmann, "General formulae for the transformation of the elastic piezoelectric and dielectric constants," USASRDL Technical Report 2051, US Army Signal Research and Development Laboratory, Fort Monmouth, NJ, 15 May 1959, 87pp. (DA Task 3-99-12-101).

[35] F. B. Hildebrand, Methods of Applied Mathematics, Prentice-Hall, Englewood Cliffs, NJ, 1952.

[36] F. I. Fedorov, Theory of Elastic Waves in Crystals, Plenum Press, New York, 1968

[37] Lord Kelvin (Wm. Thomson), "Elements of a mathematical theory of elasticity," Philos. Trans. Roy. Soc. London, pp. 481-498, 1856.

[38] Landolt-Börnstein, Numerical Data and Functional Relationships in Science and Technology, New Series, Group III: Crystal and Solid State Physics, Volumes III/1, 1966; III/2, 1969; III/3, 1969; III/9, 1974; III/11, 1979; III/16a, 1981; III/16b, 1982; III/17a, 1982; and III/29a, 1992. Springer-Verlag, Berlin, New York.

[39] M. Levy, H. E. Bass, and R. Stern, Eds., Handbook of Elastic Properties of Solids, Liquids, and Gases, Academic Press, San Diego, CA, 2001. Vol. I, ISBN: 0-12-445761-4; Vol. II, ISBN: 0-12-445762-2; Vol. III, ISBN: 0-12-445763-0.

[40] A. Ballato, "Voigt-Reuss-Hill Moduli for ferroelectric aggregates," IEEE $15^{\text {th }}$ Intl. Symp. Applications of Ferroelectrics Proc., pp. 208-211, Sunset Beach, NC, July-August 2006.

[41] A. Ballato, "Elastic moduli, and their temperature coefficients, of piezoelectric and nonpiezoelectric polycrystalline aggregates," IEEE Intl. Ultrasonics Symp. Proc., pp. 2250-2254, October 2006, Vancouver BC, Canada.

[42] R. B. Wright and D. M. Stuart, "Some experimental studies of the vibrations of quartz plates," J. Res. N. B. S., vol. 7, pp. 519-553, June 1931. (RP 356)

[43] H. J. Welker, "Discovery and development of III-V compounds," IEEE Trans. Electron Devices, vol. ED-23, no. 7, pp. 664-674, July 1976.

[44] W. A. Harrison, Electronic Structure and the Properties of Solids, Dover, New York, 1989.

[45] S. Tokmakova, "Cuts with a negative Poisson's ratio in Si," paper 2aPAb3, 141 ${ }^{\text {st }}$ Meeting, Acoust. Soc. Am., Chicago, IL, June 2001. Abs.: J. Acoust Soc. Am., vol. 109, no. 5, pt. 2, p. 2347 , May 2001.

[46] S. P. Tokmakova, "Cuts with negative Poisson's ratio in alloys and rocks," paper 5aPA7, $143^{\text {rd }}$ Meeting, Acoust. Soc. Am., Pittsburgh, PA, June 2002. Abs.: J. Acoust Soc. Am., vol. 111, no. 5, pt. 2, p. 2465, May 2002 